\title{
Reliability and Validity Studies of Externality of Happiness Scale Among Turkish Adults
}

\author{
Murat Yildirim, MSc, PhD Student \\ Ufuk Barmanpek, MA, PhD Student \\ Ahmad A. H. Farag, MA, PhD Student \\ University of Leicester, Leicester, United Kingdom
}

Doi: 10.19044/esj.2018.v14n14p1 $\quad$ URL:http://dx.doi.org/10.19044/esj.2018.v14n14p1

\begin{abstract}
Externality of happiness is a psychological construct that refers to the degree to which individuals perceive their level of happiness as beyond their control and mostly dependent to external factors. The aim of this study was to examine the reliability and validity of the Externality of Happiness scale $(\mathrm{EOH})$ among a Turkish adult sample. A total of 230 participants (152 males and 78 females; mean age $=37.8$ years, $S D=9.1$ ) completed self-report measures of externality of happiness, life satisfaction, flouring, self-esteem, and fear of happiness. Exploratory and confirmatory factor analysis supported a one-factor structure for the $\mathrm{EOH}$. The $\mathrm{EOH}$ was found to be negatively correlated with life satisfaction, flourishing, and self-esteem and positively correlated with fear of happiness. The scale also showed incremental value over self-esteem in predicting life satisfaction. Furthermore, the scale was found to be discriminated from fear of happiness. Moreover, evidence was provided for internal-consistency reliability. Overall, the findings suggested that Turkish version of EOH had adequate reliability and validity scores and that it can be used as a useful measurement tool to assess externality of happiness beliefs in future clinical practice and research.
\end{abstract}

Keywords: Externality of happiness, reliability, validity, satisfaction with life, flourishing, fear of happiness, self-esteem

\section{Introduction}

In recent years, positive psychologists have increasingly become interested in the theoretical conceptualization of important positive psychological constructs and the usefulness of these constructs to predict wellbeing. Particularly, as a positive construct, happiness was found to be fundamental ingredient to the good life (King \& Napa, 1998). However, over the last few years, researchers have argued that many researchers have largely 
focused on the positive emotions regulation (e.g. happiness, optimism, joy, contentment), but less on different views around happiness (e.g. Joshanloo et al., 2014). Thus, they proposed various views around happiness such as fear of happiness, the beliefs that happiness results in bad things to happen (Joshanloo, 2013), and fragility of happiness, the beliefs that happiness is temporary and fragile (Joshanloo et al., 2015). These constructs were found to be negatively associated with subjective and psychological well-being (e.g., Yildirim \& Belen, 2018; Joshanloo et al., 2015; Joshanloo, 2013).

Joshanloo (2017) has recently proposed another new construct of happiness named externality of happiness. Externality of happiness can be defined as the degree to which people perceive their level of happiness as beyond their control and mostly dependent to external factors. Luck, fate, destiny, and life's situation can be considered as the most common external factors that determine happiness, although attribution of happiness to external factors may vary significantly from person-to-person and culture-to-culture. Joshanloo (2017) argued that holding externality of happiness beliefs could signify a lack of perceived control over persons' happiness.

Theoretical context of externality of happiness construct is derived from locus of control theory (Rotter, 1966). Hence, it would be useful to briefly outline the key aspects of the locus of control theory in order to understand externality of happiness. Rotter (1966) defined locus of control as a global belief that the extents to which a person believes that s(he) has control over his/her life events. The theory was proposed to explain the connections between personal life events and the associated outcomes. Locus of control can typically be considered as internal locus of control and external locus of control. Individuals high in internal locus of control are prone to base personal life's events and consequences (e.g., successes, failures) to their own wills and efforts. However, individuals high on external locus of control incline to believe that life's events and outcomes are determined by external factors, which are outside their influence and control (e.g., fate, destiny, luck, powerful others). Levenson (1974) expanded the concept of locus of control by suggesting three distinct, but related dimensions of locus of control: internality, powerful others, and chance. Internality denotes internal locus of control and that represents the notion that life's outcomes are shaped by one's own thoughts, emotions and behaviors. Powerful others reflect external locus of control and that represents the idea that life's outcomes are determined by powerful others. Chance referring external locus of control represents the idea that life's outcomes are usually incidental.

There is a wealth of empirical support that internal locus of control and external locus of control are associated with different psychological constructs. By and large, internal locus of control is largely associated with positive psychological constructs, while external locus of control is 
predominantly related with negative psychological constructs. Studies showed that higher level of internal locus of control is associated with lower level of depression, anxiety and stress, and higher level of using adaptive coping strategies, quality of life, delaying gratification, and taking responsibility. On the other hand, higher level of external locus of control is found to be related to higher level of depression, anxiety and stress, higher level of using maladaptive coping strategies, lower level of quality of life, delaying gratification and taking responsibility (Sharif, 2017; Cheng, Cheung, Chio, \& Chan, 2013; van Dijk, Dijkshoorn, van Dijk, Cremer, \& Agyemang, 2013; Zampieri \& de Souza, 2011; Strudler, Wallston \& Wallston, 1978).

Joshanloo (2017) argued that by applying the dynamic of locus of control to happiness, it would be possible to identify the determinants of happiness (internality vs externality). According to him, sources of happiness fall on a continuum, with one end of the spectrum indicating external factors (e.g., destiny, fate), while the other end of the spectrum indicating internal factors (e.g., individual wills, efforts)

To operationalize externality of happiness construct, Joshanloo (2017) modified items on the locus of control scale (Hill, 2011), which is widely used scale in measuring to what extent people have control over the events in their life. In the scale development process, two Korean and one Iranian sample data were used to provide initial psychometric properties and evidence of validation. Through a series of confirmatory factor analysis, the author proposed a four-item single factor scale, with satisfactory reliability and construct validity to measure externality of happiness beliefs.

Studies using externality of happiness scale found that higher scores on the scale were associated with lower scores on positive affect, life satisfaction, resilience and personal growth initiative, while higher scores on the scale were associated with higher score on negative affect across cultures such as Korean and Iran (Joshanloo, 2017). Additionally, in the same studies, the results of the mediation analysis revealed that resilience and personal growth initiative partially mediated the relationship between externality of happiness and subjective well-being. The author concluded that having the belief that one has inadequate internal control over his/her level of happiness could be a dysfunctional on his or her well-being.

The present study used the externality of happiness scale developed by Joshanloo (2017). Because of its shortness properties, the scale can be useful for several reasons. First, the scale would provide an invaluable opportunity for data collection when time is limited. Second, when there are a large number of other measurements to add within a package of questionnaire survey, the short scales do not take up too much space and prevent the survey to be overly long. Third, the applications of the short scales are more practical in identifying the processes and changes in the therapeutic sessions and reducing 
the amount of the time and resources that practitioners and clients need to invest during the therapy sessions.

Although Joshanloo (2017) has argued theoretical and empirical unidimensionality of externality of happiness scale, examination of structural properties of the scale would be useful in Turkish context for cross-cultural comparison of the externality of happiness research outcomes. As such, the purpose of this study was to adapt the externality of happiness scale into Turkish and analyse its reliability and validity among Turkish adults.

In the present study, we particularly aimed to provide evidence for construct validity, convergent validity, incremental validity, discriminant validity, and internal-consistency reliability. To this end, we made several assumptions regarding the study aims. With regards to construct validity, we expected that exploratory factor analysis would uncover one underlying factor structure of the sets of items on the measure, and that confirmatory factor analysis would verify the emerging factor structure through exploratory factor analysis. This assumption was rest on the previous evidence that externality of happiness was found to be unidimensional (Joshanloo, 2017). In terms of convergent validity, we expected that externality of happiness would negatively correlated with satisfaction with life, flourishing, and self-esteem, while externality of happiness would positively correlate with fear of happiness. This expectation was based on the idea that those who have high level of externality of happiness would report low life satisfaction, flourishing, and self-worth, and high aversion to happiness. Concerning incremental validity, we hypothesized that externality of happiness would show incremental value over self-esteem in predicting satisfaction with life. As to discriminant validity, we assumed that externality of happiness would be separable from theoretically related yet different construct. Particularly, we expected that externality of happiness would be distinct from fear of happiness by examining their factor structures both simultaneously and independently. Finally, we anticipated that items on the externality of happiness measure would be internally consistent.

\section{Method}

\section{Participants}

The sample of this study consisted of 230 Turkish adults drawn from the general population: 152 men $(66.1 \%$ ) (age range $19-64$, mean $=38.76, S D$ $=9.39)$ and 78 women $(33.9 \%)$ (age range $18-54$, mean $=35.85, S D=8.19)$. A total of $184(80 \%)$ were married, $43(18.7 \%)$ were single, and $3(1.3 \%)$ were widowed. As to their education level, the participants predominantly graduated from university $119(51.7 \%)$ with postgraduate $72(31.3 \%)$ being the next highest reported education qualification and high school 25 (10.9\%), college $9(3.9 \%)$, and secondary-primary school $5(2.2 \%)$, respectively. With 
regards to socioeconomic status, $150(65.2 \%)$ of the participants perceived their status as medium, $41(17.8 \%)$ as low, $24(10.4 \%)$ as very low, and 15 $(6.5 \%)$ as high. Participants were recruited via a convenience sampling method, i.e., participants were those who were online and using social media at the time of data collection and who agreed to take part the study. Participation in the study was voluntary and the participants' confidentiality and anonymity were assured.

\section{Measures}

Externality of Happiness Scale (EOH; Joshanloo, 2017). The EOH is designed to measure the degree to which individuals perceive their level of happiness as beyond their control and mostly dependent to external factors. The scale is a unidimensional scale comprising of 4 items (e.g., My happiness is controlled by forces outside my control). Each of the items on the scale is rated on a 7-point Likert scale, ranging from 1 (strongly disagree) to 7 (strongly agree). Items on the scale are summed to obtain a global score, ranging from 4 to 28 . Higher scores on the scale show higher level of externality of happiness beliefs.

Fear of Happiness Scale (FHS; Joshanloo, 2013; Joshanloo et al., 2014). The FHS is a unidimensional scale comprising of 5 statements (e.g., Having lots of joy and fun causes bad things to happen.). The scale measures the global belief that experiencing of positive emotions, particularly to an extreme degree, may have negative outcomes. Participants are required to answer each of the statements on the scale on a 7-point Likert scale, ranging from 1 (strongly disagree) to 7 (strongly agree). Items on the scale are summed to obtain a global score. Higher scores on the scale represent higher level of fear of happiness. The Turkish adaptation of the scale has shown satisfactory evidence of reliability and validity (Yildirim \& Aziz, 2017). Cronbach's alpha coefficient for the scale in the present study was .88.

Satisfaction with Life Scale (SWLS; Diener, Emmons, Larsen, \& Griffin, 1985). The scale is an extensively used measure of life satisfaction. The SWLS was constructed to measure people's global judgements of life satisfaction. The scale was found to be unidimensional scale with strong internal reliability (Diener et al., 1985). The SWLS includes 5 items (e.g., In most ways my life is close to my ideal) rated on a 7-point Likert scale, ranging from 1 (strongly disagree) to 7 (strongly agree). An overall score, ranging from 7 to 35 , can be created by summing all the items on the scale. Higher scores on the scale refer to higher level of life satisfaction. The scale was adapted into Turkish culture by Durak, Senol-Durak, and Gencoz (2010). Cronbach's alpha coefficient for the scale in the present study was .81.

Flourishing Scale (FS; Diener et al., 2010). The scale is developed to measure social-psychological well-being from significant areas of human 
functioning including relationships, life purpose, self-esteem and optimism. The FS consists of 8 items (e.g., My social relationships are supportive and rewarding) and each item is rated on a 7-point Likert scale, ranging from 1 (strongly disagree) to 7 (strongly agree). To create a total score, range from 8 to 56 , items on the scale are summed. Higher scores on the scale indicate that individuals perceive themselves as satisfying in significant domains of functioning. Turkish adaptation of the scale was conducted by Telef (2001). Cronbach's alpha coefficient for the scale in the present study was .85 .

Rosenberg Self-Esteem Scale (RSES; Rosenberg, 1965). The scale is a widely used measure of global self-worth. The RSES is comprised of 10 items including both positive (e.g., On the whole, I am satisfied with myself) and negative (e.g., All in all, I am inclined to feel that I am a failure) statements about the self. Each of the items on the scale is rated using a 4-point Likert type scale ranging from 4 (strongly agree) to 1 (strongly disagree). Prior to creating a total score, all negative items are reversed. The overall scores range from 0-40, with higher scores referring to higher levels of self-worth. The scale was adapted into Turkish language by Çuhadaroğlu (1986). Cronbach's alpha coefficient for the scale in the present study was .66.

\section{Procedure}

The original Externality of Happiness scale was translated from English to Turkish by three bilingual academics using a translation and backtranslation procedure (Brislin, 1970). Another two bilingual academics translated it back from Turkish to English. All bilingual academics hold PhD degrees and are fluent in both languages. Afterwards, language equivalency was examined between the translation and back translation forms. After assurance of language consistency and clarity, the scale conducted alongside the aforementioned scales.

The participants were recruited using e-mails, social media sites, forums, blogs, and referral from friends. A secured online software was used to collect the data. Respondents were given a link where they had to click the link to access the study. Because the study was a web-based survey, an informed consent form was given at the first page of the online survey. The online informed consent form included information regarding the aim of the study, assurance of anonymity of the personal information, storing and disposing the data after the data collection. Respondents were also informed regarding their right to opt out of the study, both during and after the involvement (e.g., opt out of the study at any time point without giving any reasons). After reading the online informed consent form, the respondents were asked to respond whether they were willing to take part in the survey. Those who agreed to participate the study were only allowed to proceed and those who did not agree to participate were automatically quitted from the 
survey. The questionnaires were presented to the participants in the same order. No compensation was given to participants in return to their participation.

\section{Statistical Analysis}

Using a split-sample method for cross validation (see Yildirim \& Aziz, 2017), participants were randomly divided into two subsamples of equal size (Sample 1, $N=115$; Sample 2, $N=115$ ). Exploratory factor analysis was conducted on the data from one subsample to explore underlying factor structure of the set of items. Confirmatory factor analysis was then performed on the data from the other subsample to examine structure validity of the scale. Apart from that, convergent validity, incremental validity, discriminant validity, and reliability analyses were performed on the total sample of 230 . Pearson product-moment correlation was estimated to establish convergent validity. Incremental validity was examined using hierarchical multiple regression analysis. Discriminant validity was tested utilizing confirmatory factor analysis. The Cronbach's alpha coefficient was calculated for the internal consistency of the scale. The data were analysed using SPSS 24 for Windows and AMOS 24 for Windows.

\section{Results}

\section{Descriptive statistics}

Table 1 presents mean, standard deviation, skewness and kurtosis values for each item referring to Externality of Happiness scale as well as variables used in the present study. Investigation of the distribution indices in Table 1 showed that deviation from normality is not large enough and nonnormality is not a serious issue as all skewness and kurtosis values fell within the "acceptable" range of -/+2 (Curran, West, \& Finch, 1996; George \& Mallery, 2010). This was further supported using $Z$ score test statistic. By adapting $Z$ score procedure, all raw scores were initially converted into $Z$ scores and then scores outside the range of $-/+3.29$ are considered to be univariate outliers and violate the assumptions of parametric statistics (Tabachnick \&Fidell 2001). No score has been detected as univariate outliers to violate normality assumption. 
Table 1. Descriptive statistics for each of the items on Externality of Happiness scale and study variables

\begin{tabular}{lcccccc}
\hline & & & \multicolumn{3}{c}{ Skewness } & \multicolumn{2}{c}{ Kurtosis } \\
\cline { 5 - 7 } & Mean & $S D$ & Statistic & $S E$ & Statistic & $S E$ \\
\hline Items on Externality of happiness & & & & & & \\
Item 1 & 4.31 & 1.84 & -0.42 & 0.16 & -1.28 & 0.32 \\
Item 2 & 3.76 & 2.10 & -0.01 & 0.16 & -1.50 & 0.32 \\
Item 3 & 2.47 & 1.90 & 0.95 & 0.16 & -0.61 & 0.32 \\
Item 4 & 3.14 & 2.04 & 0.47 & 0.16 & -1.31 & 0.32 \\
Study variables & & & & & & \\
Externality of happiness & 13.68 & 5.20 & 0.27 & 0.16 & -0.61 & 0.32 \\
Fear of happiness & 14.21 & 8.01 & 0.58 & 0.16 & -0.70 & 0.32 \\
Life satisfaction & 21.53 & 6.51 & -0.46 & 0.16 & -0.61 & 0.32 \\
Flourishing & 40.01 & 8.07 & -0.88 & 0.16 & 0.56 & 0.32 \\
Self-esteem & 28.29 & 3.35 & 0.10 & 0.16 & 0.19 & 0.32 \\
\hline Note: $S D=$ Stannyyyy
\end{tabular}

Note: $S D=$ standard deviation; $S E=$ standard error.

\section{Exploratory Factor Analysis}

Exploratory factor analysis (EFA) was performed to examine the underlying factor structure of the Externality of Happiness measure on the first randomly chosen half of the sample $(\mathrm{N}=115)$. A principal components analysis extraction method without rotation (as all items were expected to load on a single factor) was used. Bartlett's test of sphericity indicated that the correlation matrix was adequate for conducting EFA, $\chi^{2}=22.07, \mathrm{df}=6, p<$ .001 . Kaiser-Meyer-Olkin measure of sampling adequacy $(\mathrm{KMO}=.63)$ revealed that the data was satisfactory for factor analysis by exceeding the recommended criterion of .60 as "good" (Tabachnick \& Fidell, 2001; Kaiser, 1960).

We used several criteria to determine the number of factors to be retained: Kaiser's (1960) Eigenvalue greater than 1 method, Cattell's (1966) Scree test, and Horn's (1965) Parallel analysis of Monte Carlo simulations. Kaiser's criterion selects only the factors that have an eigenvalue greater than one. Although this criterion is sensitive to misinterpret the most appropriate number of factors, EFA generated a one-factor solution with eigenvalues greater than 1, which accounted for $39.19 \%$ and $22.27 \%$ of total variance for the first two factors, respectively. Eigenvalues for the first two factors were respectively 1.57 and .89 . Despite the fact that the Scree test procedure carries researchers' biases to determine the number of factors, inspection of Scree plot visually demonstrated that the plot sharply became flat at the second eigenvalue supporting the one-factor solution. 


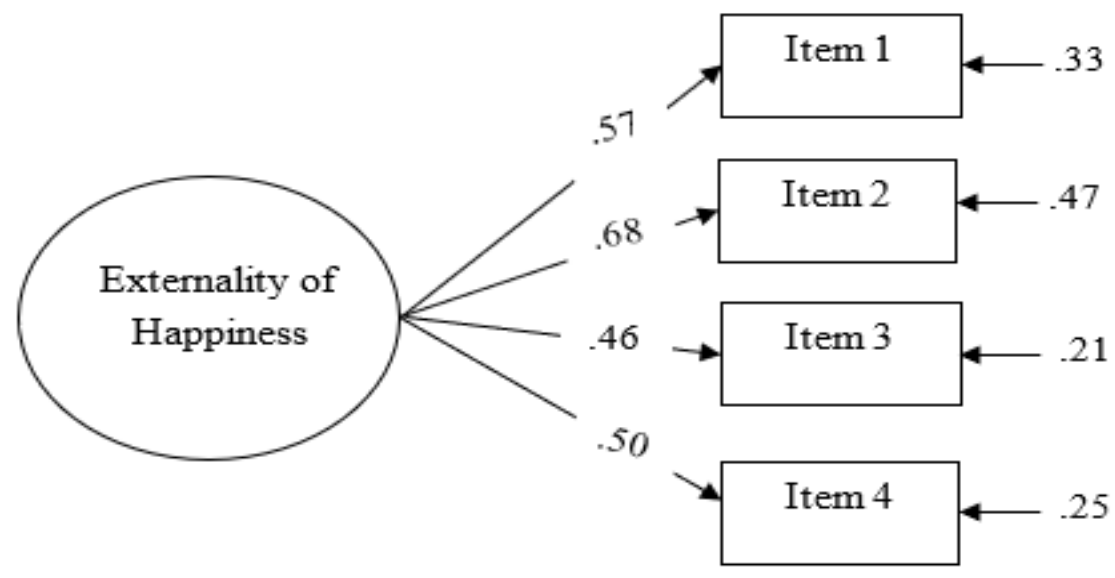

Figure 1. Standardized Factor Loadings of Externality of Happiness Scale

Due to the drawbacks with above-referred two extraction methods, we further taken into account parallel analysis, which have been suggested as the most accurate method for retaining the number of factors because of indicating the least variability and sensitivity to various factors (Ledesma \& ValeroMora, 2007; Zwick \& Velicer, 1986). Parallel analysis confirmed a one-factor solution, because only the first eigenvalue (1.57) obtained through EFA in our actual dataset was greater than the first mean eigenvalue (1.21) obtained from 1,000 generated random sets of data with 115 subjects and 4 variables. Collectively, these results suggest that a one-factor solution was appropriate for our dataset.

Table 2 presents a list of the items referring to externality of happiness

Table 2. List of the items referring to Externality of Happiness Scale both in English and Turkish and their corresponding factor loadings

\begin{tabular}{|c|c|c|c|}
\hline Items & Language & Statements & Loadings \\
\hline & English & My happiness is controlled by forces outside my control. & \\
\hline Item 1 & Turkish & $\begin{array}{l}\text { Mutluluğum benim kontrolümde olmayan faktörler } \\
\text { tarafindan belirlenir. }\end{array}$ & .73 \\
\hline Item 2 & $\begin{array}{l}\text { English } \\
\text { Turkish }\end{array}$ & $\begin{array}{l}\text { It's a matter of fate whether or not someone is happy. } \\
\text { Bir insanin mutlu olup olmamast onun kaderi ile alakalıdir. }\end{array}$ & 60 \\
\hline Item 3 & English & $\begin{array}{l}\text { My happiness is determined by accidental happenings and } \\
\text { luck. }\end{array}$ & .56 \\
\hline & $\begin{array}{l}\text { Turkish } \\
\text { English }\end{array}$ & $\begin{array}{l}\text { Mutluluğum şans ve tesadüfler tarafindan belirlenir. } \\
\text { I feel that I have little influence over my level of happiness. }\end{array}$ & \\
\hline Item 4 & Turkish & $\begin{array}{l}\text { Mutluluk seviyem üzerinde etkimin az olduğunu } \\
\text { düșünüyorum. }\end{array}$ & .60 \\
\hline
\end{tabular}

Note: Extraction Method: Principal Component Analysis.Factor loadings were interpreted using Tabachnick and Fidell's (2007) criterion where loadings greater than .71 are assessed as excellent, .63 very good, .55 good, .45 fair, and .32 poor. As shown in Table 2, the factor loadings of the four items were all good by exceeding .55 .

measure in both English and Turkish and their corresponding factor loadings. 


\section{Confirmatory Factor Analysis}

In keeping with the EFA results and original form of the scale, a unidimensional factor solution was tested on the second set of the data using confirmatory factor analysis (CFA). CFA with maximum likelihood estimation, which requires normal distribution of the data and continuous variables, was performed on AMOS. The unidimensional factor solution assumed a single latent variable named externality of happiness and four observed variables. The error terms in the hypothesised model were treated as uncorrelated.

Multiple fit indices can be used when the assessment of model fit to the data is made. Although no index per se is adequately reliable, it is preferable to use several indices simultaneously to make a correct decision. Based on recent recommendation, following fit indices were used to evaluate the model fit: the ratio of chi square $\left(\chi^{2}\right)$ to degrees of freedom (df) known as CMIN/DF, root mean square error of approximation (RMSEA), standardised root mean square residual (SRMR), goodness of fit index (GFI), adjusted goodness of fit index (AGFI), comparative fit index (CFI), and normed fit index (NFI) (Hu \& Bentler, 1999; Kline, 2005). Apart from these, we also reported Chi-squared statistic $\left(\chi^{2}\right)$ which should be insignificant yet sensitive to sample size, and degree of freedom. For each of fit indices, following values are used whether the model fit is acceptable: (a) the CMIN/DF should be maximum of 5 (Sümer, 2000), (b) RMSEA should fall within 0 and 1 (MacCallum, Browne, \& Sugawara, 1996), (c) SRMR should range between 0 and .08 (Hu \& Bentler, 1999), and (d) GFI, AGFI, CFI, and NFI should fall within .90 and 1 (Hu \& Bentler, 1999, Tabachnick \& Fidell, 2001).

Goodness of fit measures emerged through CFA indicated that the model was a good presentation of the data $\left(\chi^{2}=3.321\right.$, df $=2, p>.001$; $\mathrm{CMIN} / \mathrm{DF}=1.661 ; \mathrm{GFI}=.985 ; \mathrm{AGFI}=.926 ; \mathrm{CFI}=.974 ; \mathrm{NFI}=.921$; RMSEA = .076; SRMR = .0398). The parameter estimates showed that all the items had acceptable factor loadings onto the latent factor and the standardized factor loadings for item 1-4 were respectively .57, .68, .46, and.50 (see Figure 1). The results confirmed the unifactorial structure of the externality of happiness measure in the Turkish language.

\section{Convergent validity}

Apart from EFA and CFA where the data was randomly divided into two equal groups for the separate analyses, all the subsequent reliability and validity analysis were performed on the total sample of 230.

To provide evidence of the convergent validity of the Externality of Happiness measure, we investigated the association between externality of happiness and satisfaction with life, flourishing, self-esteem, and fear of happiness. Results of the correlation analyses presented in Table 3. As seen in 
Table 3, higher scores on externality of happiness were associated with lower scores on satisfaction with life, flourishing, and self-esteem while higher scores on the measure were associated with higher scores on fear of happiness.

Table 3. Correlations between Externality of Happiness and the study variables

\begin{tabular}{lccccc}
\hline & 1 & 2 & 3 & 4 & 5 \\
\hline 1. Externality of Happiness & 1 & & & & \\
2. Fear of Happiness & $.255^{* *}$ & 1 & & & \\
3. Satisfaction with Life & $-.169^{*}$ & -.110 & 1 & & \\
4. Flourishing & $-.163^{*}$ & $-.143^{*}$ & $.423^{* *}$ & 1 & \\
5. Self-esteem & $-.145^{*}$ & $-.143^{*}$ & $.228^{* *}$ & $.486^{* *}$ & 1 \\
\hline$* * . p<0.01 ; * . p<0.05$ & & & & &
\end{tabular}

\section{Incremental Validity}

To ascertain usefulness of the measure, it is meaningful to provide evidence of incremental validity. To this end, we conducted a series of hierarchical regression analyses to examine whether externality of happiness indicates incremental value in predicting satisfaction with life and flourishing after controlling for the self-esteem. In each of the regression models, satisfaction with life and flourishing were considered as dependent variables, whereas externality of happiness and self-esteem were treated as independent variables. For the first two-step regression analysis, self-esteem was entered into the model in the first step and reached statistical significance level in predicting satisfaction with life, $\left[F[1,229]=12.52, r=.23, r^{2}=.052\right.$, adj. $r^{2}=$ $.048, p<.01]$. In the second step, the inclusion of the externality of happiness produced a significant $\mathrm{r}^{2}$ change $\left(\Delta \mathrm{r}^{2}=.019, \Delta F[2,229]=4.60, p=.034\right)$, with externality of happiness indicating a statistical significant regression coefficient $(\beta=-.17, p=.033)$. For the second two-step regression analysis, self-esteem was again entered into the model in the first step and produced significant result in predicting flourishing $\left[F[1,229]=70.59, r=.47, r^{2}=.24\right.$, adj. $\left.r^{2}=.23, p<.01\right]$. In the second step, adding of externality of happiness did not produce a significant $\mathrm{r}^{2}$ change $\left(\Delta \mathrm{r}^{2}=.009, \Delta F[2,229]=2.62, p=.107\right)$, with externality of happiness showing insignificant regression coefficient $(\beta=$ $-.15, p=.107)$. The results suggest that externality of happiness is able to account for unique variance in satisfaction with life, but not in flourishing.

\section{Discriminant Validity}

To establish discriminant validity of the Externality of Happiness scale, we examined the factor structure of the scale against Fear of Happiness scale. Confirmatory factor analysis was performed to compare the goodness of fit statistics for two different competing factor solutions. The first solution was the one-factor solution, proposing that all the items referring to the Externality of Happiness and Fear of Happiness scales measure one global 
factor. The second solution was the two-factor solution, assuming that Externality of Happiness and Fear of Happiness are two separate constructs. Table 4 shows goodness of fit indices for the abovementioned two hypothesized solutions. As shown in Table 4, a good fit to the data was observed for the two-factor solution by meeting the criteria for goodness of fit. The two-factor solution clearly presented a better fit to the data than the one-factor solution. These results suggest that Externality of Happiness served a distinct construct from the Fear of Happiness.

\section{Reliability}

Reliability analysis for the four items on the measure was conducted using Cronbach's alphas coefficient (Cronbach, 1951). The results showed an alpha coefficient of .56, just below the > .60 (Nunnally, 1967).

\section{Conclusion}

The main goal of this study was to examine the reliability and validity of Turkish translation of Externality of Happiness scale measuring the idea that individuals perceive their level of happiness as beyond their control and mostly dependent to external factors, not by one's own will.

EFA and CFA were performed in order to examine the factor structure of the externality of happiness scale. Results of the EFA and CFA showed that the scale had a single factor solution. In the line with the previous research (e.g., Joshanloo, 2017), the unidimensional factor structure of the Turkish version of Externality of Happiness scale was confirmed.

Concerning convergent validity, externality of happiness was negatively correlated with satisfaction with life, flourishing, and self-esteem and positively correlated with fear of happiness.

Table 4. Goodness of fit statistics for one- and two-factor models

\begin{tabular}{lccccccccc}
\hline $\begin{array}{l}\text { Competing } \\
\text { models }\end{array}$ & $\chi^{2}$ & df & CMIN/DF & RMSEA & SRMR & GFI & AGFI & CFI & NFI \\
\hline $\begin{array}{l}\text { One-factor } \\
\text { solution }\end{array}$ & 90.446 & 27 & 3.35 & 0.101 & 0.083 & 0.913 & 0.855 & 0.881 & 0.841 \\
$\begin{array}{l}\text { Two-factor } \\
\text { solution }\end{array}$ & 41.531 & 26 & 1.597 & 0.051 & 0.049 & 0.962 & 0.935 & 0.971 & 0.96 \\
\hline
\end{tabular}

Note. $\chi^{2}=$ Chi-square $\mathrm{df}=$ degree of freedom; CMIN/DF $=$ ratio of chi square to degrees of freedom; RMSEA = Root Mean Square Error of Approximation; SRMR = Standardized Root Mean Square Residual GFI = Goodness of Fit Index; AGFI = Adjusted Goodness of Fit Index; $\mathrm{CFI}=$ Comparative Fit Index; NFI = Normed Fit Index.

Considering that externality of happiness may be detrimental to mental health (Joshanloo, 2017), confirming and expanding previous link between externality of happiness and mental health would be useful in the application of clinical and counselling psychology. 
As to incremental validity, fear of happiness was shown to have incremental value above the self-esteem to predict life satisfaction, but not flourishing. This suggests that externality of happiness is uniquely associated with satisfaction with life and uniquely important to understand life satisfaction, a critical domain of subjective well-being. However, externality of happiness is not uniquely related to flourishing, although a negative link between the two was observed. This may be due to the fact that although both satisfaction with life and flourishing are two vital ingredients of well-being, they are two distinct, but related concepts, with different theoretical underpinning, correlates, causes, and outcomes (Seligman, 2011; Diener et al., 2010; Shah \& Marks 2004; Keyes, 2002).

Additionally, a series of confirmatory factor analysis verified distinctiveness of externality of happiness from fear of happiness. Not surprisingly, a two-factor solution was found to be superior to one-factor solution, suggesting that the externality of happiness and fear of happiness are two distinct yet related constructs. To support discriminant validity, this provides the first test of whether externality of happiness can be discriminated from fear of happiness. This is meaningful as externality of happiness is also considered lay beliefs as fear of happiness and fragility of happiness (Joshanloo, 2013; Joshanloo et al., 2015) that are negatively associated with well-being.

The internal consistency reliability was found to be just below the acceptable criterion of .60. In previous study, Joshanloo (2017) reported satisfactory reliability statistic across two different samples, Korean and Iranian. However, in that study, the samples comprised purely of students. The inconsistency between the results of that study and the present study may be due to the characteristics of the sample used in the studies, because sample characteristics can result in different outcomes of the same variables (Yildirim $\&$ Belen, 2018). It could also be due to the fact that unlike previously studied cultures (e.g., Korea), Turkey obviously has distinct cultural, political, and economical background and this variation could lead to inconsistent results (Yildirim \& Belen, 2018). Another reason of poor internal consistency could be pertaining to low number of items on the scale (Tavakol \& Dennick, 2011). This inconsistency undoubtedly calls for more research into the construct reliability for the Turkish version and versions in other cultures.

The present study provided initial evidence that the concept of externality of happiness may also hold true in the Turkish context. The results indicated that Turkish version of Externality of Happiness scale has satisfactory reliability and validity. The relevant studies on externality of happiness suggested that holding the idea that one's level of happiness is mostly determined by external factors, not by one's own will, may be detrimental on one's level of well-being (Joshanloo, 2017). Considering the 
previous and the present findings, intervention aiming to reduce externality of happiness beliefs could serve as a powerful psychological buffer to promote and enhance well-being. The adaptation of the Turkish version of the Externality of Happiness scale will promote cross-cultural comparison of the externality of happiness research outcomes. The adaptation will also contribute to better understanding of the similarities and differences in the way this construct is studied across cultures. Furthermore, providing a reliable and valid tool for the measurement of the externality of happiness in Turkey will allow researchers, healthcare professionals, educators, and policy makers, to develop, implement and assess the effects of interventions aimed at enhancing the levels of wellbeing and quality of life.

It is important to note that the present study has some limitations. First, our participants were largely males $(66.1 \%)$, married $(80 \%)$, and university graduate $(51.7 \%)$. The findings may differ in populations with other demographic characteristics. Further research should examine whether the Turkish version of Externality of Happiness scale demonstrates similar psychometric properties in other populations in an attempt to increase the generalizability of the findings. Second, the sample of the present study was recruited via a convenient sampling method. Randomly drawn sample from a target population would be fruitful to increase the reliability and validity of the results (Yildirim \& Belen, 2018). Third, previous study indicated that in comparison with traditional paper questionnaires, online questionnaires carry high response rate, less subject-related bias, less data entry error rate, more convenient and cost-effective (e.g., van Gelder, Bretveld, \& Roeleveld, 2010). Although there are advantages of web-based questionnaire, further studies should replicate the current findings using both paper version and online questionnaires for comparative analysis. Furthermore, subsequent research should establish test-retest reliability over short-time and long-time periods, and measurement invariance across gender and different cultures. In addition, the study was cross-sectional in nature, the findings are limited to draw a causal and directional conclusion. Hence, interpretation of these findings should be made cautiously.

In conclusion, the present study contributes to the current literature by showing reliability and validity of the Turkish version of Externality of Happiness scale to assess the degree to which external factors affecting one's level of happiness. Overall, the results suggest that the scale is reliable and valid serving to practitioners and researcher to easily assess externality of happiness beliefs.

\section{References:}

1. Brislin, R. W. (1970). Back-translation for cross-cultural research. Journal of Cross-Cultural Psychology, 1(3), 185-216. 
2. Cattell, R. B. (1966). The Scree test for the number of factors. Multivariate Behavioral Research, 1(2), 245-276.

3. Cheng, C., Cheung, S. F., Chio, J. H., \& Chan, M. S. (2013). Cultural meaning of perceived control: A meta-analysis of locus of control and psychological symptoms across 18 cultural regions. Psychological Bulletin, 139(1), 152-188.

4. Cronbach, C. J. (1951). Coefficients alpha and the Internal Structure of tests. Psychometrika, 16, 297-334.

5. Curran, P. J., West, S. G., \& Finch, J. F. (1996). The robustness of test statistics to nonnormality and specification error in confirmatory factor analysis. Psychological Methods, 1(1), 16-29.

6. Çuhadaroğlu, F. (1986). Adolesanlarda benlik saygisı [Self-esteem in adolescence]. Unpublished doctoral dissertation, Hacettepe University, Ankara, Turkey

7. Diener, E., Emmons, R. A., Larsen, R. J., \& Griffin, S. (1985). The satisfaction with life scale. Journal of Personality Assessment, 49(1), 71-75.

8. Diener, E., Wirtz, D., Tov, W., Kim-Prieto, C., Choi, D.W., Oishi, S., \& Biswas-Diener, R. (2010). New well-being measures: Short scales to assess flourishing, positive, and negative feelings. Social Indicator Research, 97, 143-156.

9. Durak, M., Senol-Durak, E., \& Gencoz, T. (2010). Psychometric properties of the satisfaction with life scale among Turkish university students, correctional officers, and elderly adults. Social Indicators Research, 99(3), 413-429.

10. Furnham, A. (2009). Locus of control and attribution style. In M. R. Leary, \& R. H. Hoyle (Eds.), Handbook of individual differences in social behavior (pp. 274-287). New York: Guilford Press.

11. George, D., \& Mallery, P. (2010). SPSS for windows step by step: A simple guide and reference 17.0 update (10th Ed.). Baston: Pearson.

12. Hill, R. (2011). The locus of control construct's various means of measurement. New Jersey: Will to Power Press.

13. Horn, J. L. (1965). A rationale and test for the number of factors in factor analysis. Psychometrika, 30(2), 179-185.

14. Hu, L.T., \& Bentler, P.M. (1999). Cutoff criteria for fit indexes in covariance structural analysis: Conventional criteria versus new alternatives. Structural Equation Modeling, 6, 1-55.

15. Joshanloo, M. (2013).The influence of fear of happiness beliefs on responses to the satisfaction with life scale. Personality and Individual Differences, 54(5), 647-951. 
16. Joshanloo, M. (2017). Mediators of the relationship between externality of happiness and subjective well-being. Personality and Individual Differences, 119, 147-151.

17. Joshanloo, M., Lepshokova, Z. K., Panyusheva, T., Natalia, A., Poon, W. C., Yeung, V. W. L., ... \& Tsukamoto, S. (2014). Cross-cultural validation of fear of happiness scale across 14 national groups. Journal of Cross-Cultural Psychology, 45(2), 246-264.

18. Joshanloo, M., Weijers, D., Jiang, D. Y., Han, G., Bae, J., Pang, J. S., ... \& Khilji, I. A. (2015). Fragility of happiness beliefs across 15 national groups. Journal of happiness studies, 16(5), 1185-1210.

19. Nunnally, J. C. (1967). Psychometric theory. New York: McGraw Hill.

20. Kaiser, H. F. (1960). The application of electronic computers to factor analysis. Educational and Psychological Measurement, 20(1), 141151.

21. Keyes, C. (2002). The mental health continuum: From languishing to flourishing in life. Journal of Health and Behaviour Research, 43, 207-222.

22. King, L. A., \& Napa, C. K. (1998). What makes a life good? Journal of personality and social psychology, 75(1), 156-165.

23. Kline, R.B. (2005). Principles and practice of structural equation modeling. New York: Guilford Press.

24. Ledesma, R. D., \& Valero-Mora, P. (2007). Determining the number of factors to retain in EFA: An easy-touse computer program for carrying out parallel analysis. Practical Assessment, Research \& Evaluation, 12(2), 1-11.

25. Levenson, H. (1974). Activism and powerful others: Distinctions within the concept of internal-external control. Journal of Personality Assessment, 38(4), 377-383.

26. MacCallum, R.C., Browne, M.W., \& Sugawara, H.M. (1996). Power analysis and determination of sample size for covariance structure modeling. Psychological Methods, 1(2), 130-49.

27. Rosenberg, M. (1965). Society and the adolescent self-image. Princeton, NJ: Princeton University Press.

28. Rotter, J. B. (1966). Generalized expectancies for internal versus external control of reinforcement. Psychological Monographs: General and Applied, 80(1, Whole No. 609), 1-28.

29. Seligman, M. E. P. (2011). Flourish - A new understanding of happiness and well-being - and how to achieve them. London: Nicholas Brealey Publishing.

30. Shah, H., \& Marks, N. (2004). A well-being manifesto for a flourishing society. London: The New Economics Foundation. 
31. Sharif, S. P. (2017). Locus of control, quality of life, anxiety, and depression among Malaysian breast cancer patients: The mediating role of uncertainty. European Journal of Oncology Nursing, 27, 28-35.

32. Strudler Wallston, B., \& Wallston, K. A. (1978). Locus of control and health: A review of the literature. Health Education Monographs, 6(1), 107-117.

33. Sumer, N., (2000). Yapısal eşitlik modelleri: Temel kavramlar ve örnek uygulamala. Türk Psikoloji Yazıları, 3(6), 49-73.

34. Tabachnick, B.G., \& Fidell, L.S. (2001). Using multivariate statistics (4th ed.). Needham Heights, MA: Allyn \& Bacon.

35. Tabachnick, B.G., \& Fidell, L.S. (2001). Using multivariate statistics (5th ed.). Boston, MA: Allyn \& Bacon.

36. Tavakol, M., \& Dennick, R. (2011). Making sense of Cronbach's alpha. International journal of medical education, 2, 53- 55.

37. Telef, B. B. (2001). The validity and reliability of the Turkish version of the psychological well-being. Paper presented at the 11th National Congress of Counseling and Guidance, October 3-5, Selçuk-İzmir, Turkey.

38. van Dijk, T. K., Dijkshoorn, H., van Dijk, A., Cremer, S., \& Agyemang, C. (2013). Multidimensional health locus of control and depressive symptoms in the multi-ethnic population of the Netherlands. Social Psychiatry and Psychiatric Epidemiology, 48(12), 1931-1939.

39. Van Gelder, M. M. H. J., Bretveld, R. W., \& Roeleveld, N. (2010). Web-based questionnaires: The future in epidemiology? American Journal of Epidemiology, 172(11), 1292-1298.

40. Yildirim, M., \& Aziz, I. A. (2017). Psychometric properties of Turkish form of the Fear of Happiness Scale. The Journal of Happiness \& WellBeing, 5(2), 187-195.

41. Yildirim, M., \& Belen, H. (2018). Fear of Happiness Predicts Subjective and Psychological Well-Being above the Behavioral Inhibition System (BIS) and Behavioral Activation System (BAS) Model of Personality. Journal of Positive Psychology and Wellbeing, 2(1), 1-20.

42. Zampieri, M, de Souza, EAP (2011) Locus of control, depression, and quality of life in Parkinson's disease. Journal of Health Psychology 16(6), 980-987

43. Zwick, W. R., \& Velicer, W. F. (1986). Comparison of five rules for determining the number of components to retain. Psychological Bulletin, 99(3), 432-442. 